\title{
3D Finite Element Analysis of PWA-Oil Sand Terrain System Interaction
}

\author{
Y. Li, ${ }^{1}$ S. Frimpong, ${ }^{1}$ and W. Y. Liu ${ }^{2}$ \\ ${ }^{1}$ Department of Mining and Nuclear Engineering, University of Missouri-Rolla, Rolla, MO 65409, USA \\ ${ }^{2}$ Department of Electrical and Systems Engineering, Washington University in St. Louis, St. Louis, MO 63103, USA
}

Correspondence should be addressed to Y. Li, liyinglzh@yahoo.com

Received 3 April 2012; Accepted 4 May 2012

Academic Editor: K. M. Liew

Copyright ( $) 2012$ Y. Li et al. This is an open access article distributed under the Creative Commons Attribution License, which permits unrestricted use, distribution, and reproduction in any medium, provided the original work is properly cited.

\begin{abstract}
A simulator for analyzing the interaction between the oil sand terrain and a pipe wagon articulating (PWA) system has been developed in this paper. An elastic-plastic oil sand model was built based on the finite element analysis (FEA) method and von Mises yield criterion using the Algor mechanical event simulation (MES) software. The three-dimensional (3D) distribution of the stress, strain, nodal displacement, and deformed shape of the oil sands was animated at an environmental temperature of $25^{\circ} \mathrm{C}$. The $3 \mathrm{D}$ behavior of the oil sand terrain was investigated with different loading conditions. The effect of the load and contact area on the stress and nodal displacement was analyzed, respectively. The results indicate that both the max stress and max nodal displacement increase with the load varying from 0 to $3.6 E+7 \mathrm{~N}$ and decrease with the contact area varying from 2 to $10 \mathrm{~m}^{2}$. The method presented in this paper forms the basis for evaluating the bearing capacity of oil sand ground.
\end{abstract}

\section{Introduction}

Oil sands are naturally occurring geologic formations that contain a mixture of water, clay, sand, and thick heavy oil called bitumen. Oil sands are found throughout the world and in very large formations in Canada. It is also the largest supplier of oil and natural gas. The oil produced from oil sands can be refined and used to make asphalt, gasoline, jet fuel, and some chemicals. Today, about 20 percent of the oil produced from Canadian oil sands formations are obtained via surface mining. For efficient and economic extraction and haulage of oil sands from production faces, the pipe wagon articulating (PWA) technology will be used to create and transport oil sand slurry from production faces through flexible pipeline system to link the existing hydrotransport system. Some efforts have been made to conceptualization of the PWA mechanical system [1] and detail numerical modeling for investigation of oil sand multiple-phase problem in pipeline [2]. A virtual prototype has been developed in our lab for the dynamic simulation of the oil sand terrain under dynamic load conditions by the spring-dumping model [3]. The result shows that the max displacement value increases nonlinearly with the load varying from 0 to
0.25 MPa. However, the 3D behavior of oil sands has not been studied so far, which is very important for the optimization design of the PWA system and safe operation of heavy PWA equipment. Further investigation will be made on the stressstrain and displacement-deformation analysis of the oil sands considering the different loads and contact areas.

There are a number of techniques available for estimating the behavior of soil foundations. These techniques include traditional equation [4-7], elastic method [8], and elasticplastic method [8-10]. The traditional equations provide explicit solutions for the ultimate bearing capacity. As a rule, the equations represent either empirical or semiempirical approximations of the ultimate bearing capacity and are dependent on the mode of potential failure as well as, to some extent, material properties. In this respect, selection of an appropriate equation must anticipate likely modes of potential failure. The primary disadvantage of the equations is that the method does not provide a direct solution for the distributions of stress strain and displacement deformation in two dimensions (2D) or 3D. The elastic method is available for investigation of soil behavior under the influence of external loads based on the assumption that soil is an isotropic and linear elastic material. Some 


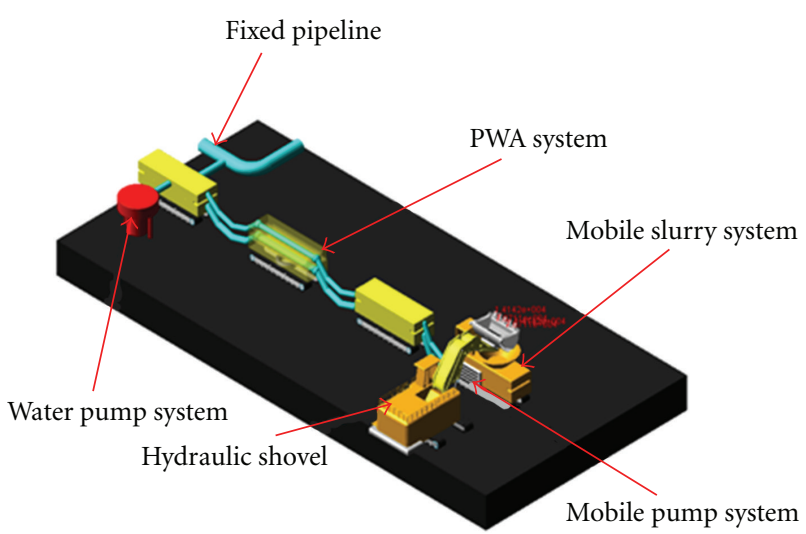

Figure 1: Conceptual design of the PWA-oil sand system.

soil such as oil sands is essentially not elastic material. As the stress-strain behavior of oil sands is responsible for the elastic and plastic displacements of oil sands when external loads act upon oil sand ground. At very low load levels, the displacements are relatively small and more or less elastic in nature; as the loads increase, displacements not only increase, but also become plastic in nature. Finally, they become so large that collapse occurs [8]. The elastic-plastic method gives more realistic predictions of the oil sand stress-strain, displacement deformation, and failure behavior than the other methods but also requires more advanced calculation facilities. In general, FE programs are used. In principle, oil sand behavior for any load and contact area configuration at any point can be calculated using these programs. In most FE programs, two failure criteria of Morhr-Coulomb and von Mises have been proposed as suitable for representing the strength of soils as engineering materials [11]. For soils material possessing both frictional and cohesive components of shear strength, the best-known criterion is undoubtedly Morhr-Coulomb criterion that takes the form of an irregular hexagonal cone in principal stress space. For soft soils such as undrained clays or oil sand material, which behaves in a "frictionless" manner, the von Mises failure criterion is appropriate. This criterion takes the form of a right circular cylinder lying along the space diagonal. The von Mises failure criterion has been successfully applied to undrained clays that have soft soil skeletons [11]. It is believed that the elasticplastic behavior of oil sands can be understood better if von Mises criterion is used.

Algor MES software offers the engineering technology for FEA needed in the civil engineering [12]. Algor can be used to analyze stress strain and displacement deformation based on the basic elastic-plastic material models.

The paper is organized as follows. In the next section PWA-oil sand system is introduced, and some assumptions are made. The theoretical model of the oil sand FEA is established in Section 3. And, simulation methodology using the Algor MES is described in Section 4. Then, an example is given for the simulation of track-oil sand terrain interaction in Section 5. Finally, some conclusions are given in Section 6.

\section{PWA-Oil Sand System}

The PWA system will facilitate the conveyance of oil sand slurry to fixed hydrotransport pipeline system. Figure 1 shows that the system consists of hydraulic shovel, mobile slurry system, mobile pump system, PWA system, water pump system, and fixed pipeline system. Figure 2 gives a conceptual design for the wagon structure and mobile slurry system. The PWA system will consist of a series of drivable pipelines linked together via wagon sections with rigid truss frames on crawlers for mobility. The PWA system is allowed to move on a soft homogeneous oil sand terrain for performing its ability. A flexible oil sand terrain, consisted of sand, bitumen, and clay, is laid on a base of natural soil. Under service condition, the oil sand terrain will have large surface deflection. The overall design requires PWA with low ground pressure either wagon or mobile slurry systems with wide track pads. A real track-oil sand system represents a complex mechanical system with many components. It is possible to simplify the system by considering only some of major factors of the system. To give a better understanding of the interaction of track with oil sands as it is subjected to loading conditions, some simplifying assumptions are made here. They are the following: (i) the oil sand terrain is subjected to static load, owing to the low operating speed; (ii) oil sand terrain is homogeneous, isotropic, elastic-plastic, and semi-infinite body; (iii) the track is rigid body without lug; (iv) the load is evenly distributed over the entire contact area.

\section{Oil Sand Model}

The bearing capacity of the oil sand terrain depends on the material characteristics and the yield function. Finite-strain theory and von Mises yield condition [13] with isotropic hardening are employed to model the oil sand terrain in order to calculate the stress, strain, nodal displacement, and deformed shade. The oil sand material is created as an elastic-plastic FE model. On an element, a node is defined at which the elements are interconnected. If the nodes in an element move relative to each other, the elements are stressed. If an external force is applied to a node, the node moves. Movement of one node means that stresses occur in an element, leading to loads on other nodes and their movement. If the stresses in one element are greater than the failure stress, an element collapses, which is indicated by the term plastic behavior. The failure criterion of the element is von Mises yield condition. The criterion interprets yielding as a purely shear deformation process which occurs when the effective shear stress $\sigma_{\mathrm{e}}$ reaches a critical value [14]. This effective stress is defined in terms of principal stress components $\left\{\sigma_{1} \sigma_{2} \sigma_{3}\right\}$ by (1):

$$
\sigma_{\mathrm{e}}=\sqrt{\frac{1}{2}\left[\left(\sigma_{1}-\sigma_{2}\right)^{2}+\left(\sigma_{2}-\sigma_{3}\right)^{2}+\left(\sigma_{3}-\sigma_{1}\right)^{2}\right]} .
$$

The von Mises criterion relates $\sigma_{\mathrm{e}}$ to the yield stress in tension $\sigma_{\mathrm{T}}$ by $\sigma_{\mathrm{e}}=\sigma_{\mathrm{T}}$. The tensile yield stress is now a material parameter and has a minimum value, which denotes the 


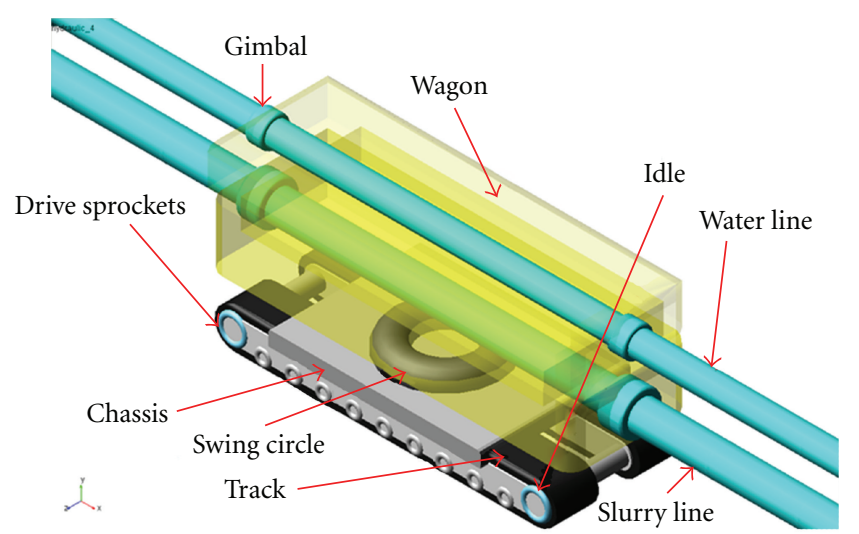

(a)

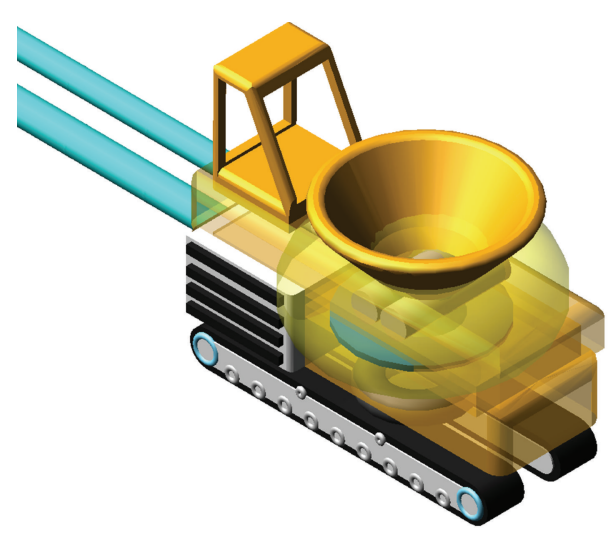

(b)

FIGURE 2: Isometric views of PWA components. (a) Wagon structure and (b) mobile slurry system.

limit of elastic behaviour and the start of plastic deformation and increases with tensile plastic strain. The variation of yield stress with plastic strain is the tensile strain hardening function. The von Mises criterion predicts that the tensile yield stress $\sigma_{\mathrm{T}}$, shear yield stress $\sigma_{\mathrm{S}}$ and compressive yield stress $\sigma_{\mathrm{C}}$ are related by $\sigma_{\mathrm{T}}=\sigma_{\mathrm{C}}=\sqrt{3} \sigma_{\mathrm{S}}$.

The FE oil sand mass model can be loaded in surface load from carriage. The FE calculation is characterized by a series of load stages. At each load stage, the stresses in the element are calculated cumulatively via the nodal displacement. By calculating the displacement of a node at each load stage, a load displacement diagram can be obtained.

\section{Algor Modeling and Simulation}

An elastic-plastic FE oil sand model is built in Algor environment. The 3D behavior of oil sand material is analyzed with the FEA of Algor MES [12], which is an engineering analysis methodology by simulating a physical event in a virtual laboratory. Algor MES combines the capabilities of kinematics and FEA to simultaneously replicate stress-strain, nodal displacement, deformation, and nonlinear material properties of the oil sand terrain, including principal stress and strain. Algor allows creating elastic-plastic material model based on the finite-strain formulation, yield function of von Mises, flow rule, and strain hardening-softening rule. The influences of the load on the stress, strain, nodal displacement and deformed shape of the oil sands can be simulated for estimating the bearing capacity using Algor MES. An outline of the elastic-plastic FEA algorithm [11], which follows the stress-strain matrix formation, is given in the structure chart in Figure 3. Figure 4 illustrates the detailed 4-step procedures for the modeling and simulation of the oil sand model. The first step involves the creation of 3D FE model with the boundary conditions, loads, and FEA parameters. The second step generates FEA model and verifies the model. The third step examines the analysis results and animates with the stress, strain, nodal displacement, and deformed shape. The fourth step plots the curves of stresstime and nodal displacement time.

\section{Simulation Results and Analysis}

The example presented below gives the $3 \mathrm{D}$ oil sand terrain behavior with the variation of the field of stress, strain, and displacement and deformation when a load is applied on the oil sand model. Figure 5 indicates a track-oil sand interaction FE model including track structure (Figure 5(a)), isometric view FE model (Figure 5(b)) and top view FE model (Figure 5(c)). The FE model is defined as the nonlinear elastic-plastic mode because of the nonlinear properties of the oil sands. The FE model with $25 \mathrm{~m}$ long, $20 \mathrm{~m}$ deep, and $10 \mathrm{~m}$ high is filled by 34000 brick elements. The boundary conditions are applied to the nodes adjacent to front, rear, left, right and bottom wall, where displacements are set as zero in the three directions of $x$, $y$, and $z$ components. Two rigid track belts are put on the oil sand model. The load applied to the FE oil sand model is assumed to be uniformly distributed edge load and gradually applied at the top boundary. The elastic-plastic oil sand material is described by four parameters, namely, the elastic-plastic properties, modulus of elasticity E, Poisson's ratio $\nu$, and strain hardening modulus $E_{T}$ and damping $c$. The parameters used in the simulation are given in Table 1 $[3,12]$. The physical properties of oil sands are obtained at an environmental temperature of $25^{\circ} \mathrm{C}$ [3]. The simulation results of 10 steps are obtained within one second (s). The load applied to the oil sand model with time steps during one second is shown in Figure 6.

5.1. Model Validation. The validity of the predefined yield stress of the oil sand material is examined first. The oil sand properties are $\rho=1600 \mathrm{~kg} / \mathrm{m}^{3}, \sigma_{y}=0.1 \mathrm{MPa}, E=10 \mathrm{MPa}$, $\nu=0.3, E_{T}=0.1 \mathrm{MPa}$, and $c=10 \mathrm{KPas}$, and the track dimensions are $L=8 \mathrm{~m}$ and $W=0.5 \mathrm{~m}$, and time step $=10$. Figures $7(\mathrm{a})-7(\mathrm{~d})$ depict the von Mises stress, strain, nodal displacement, and deformed shape (deformations are represented in a scale factor of five) contours in isometric, $\mathrm{YZ}$ slide and XZ slide, views at the load $=3.6 E+7 \mathrm{~N}$, respectively. The contour is divided into five typical areas as illustrated in Figure 5(c). It can be seen that the stress and strain values 


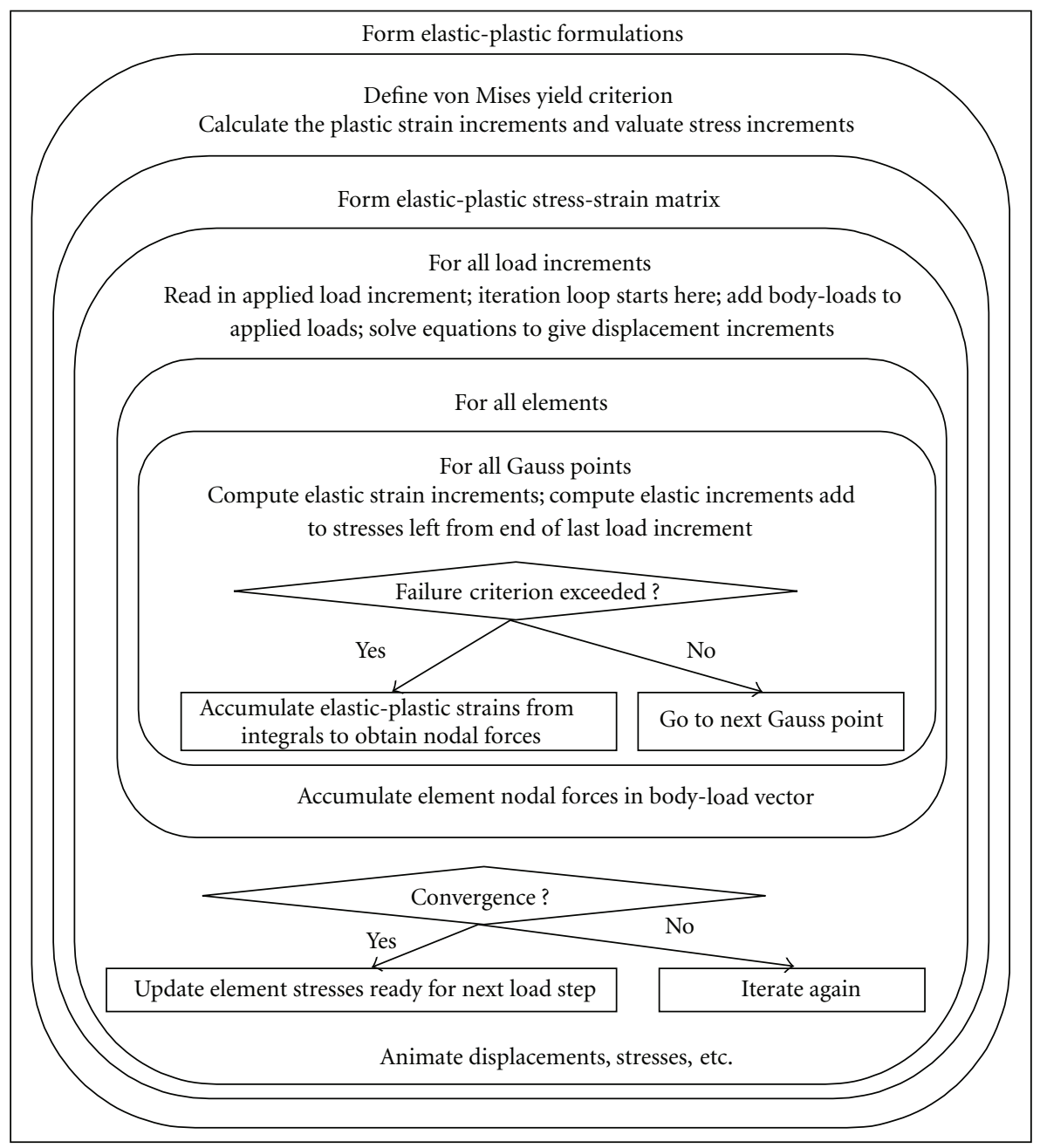

FIGURE 3: Structure chart for the 3D behavior algorithm of oil sands.

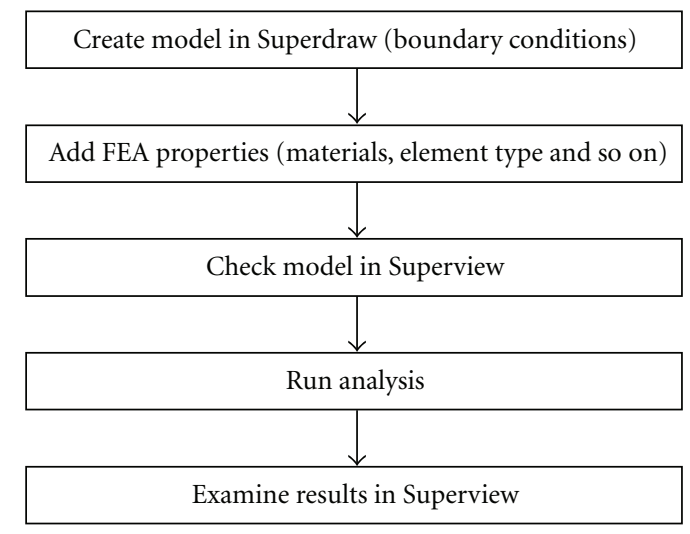

FIGURE 4: MES procedure of oil sand terrain.

decrease from the areas A to B or C in Figures 7(a) and 7(b), respectively. There are the max stress and strain fields at the area $\mathrm{A}$ and the minimum ones at the area $\mathrm{C}$. It also can be found that the nodal displacement, and deformed shape values increase from the areas A to B in Figures 7(c) and $7(\mathrm{~d})$, respectively. However, the nodal displacement and deformed shape distributions concentrate on the zones $B$. The max displacement and deformed shape are found in the center of the zone B. The stress, strain, nodal displacement and deformed shape beyond the tracks can be seen from the 


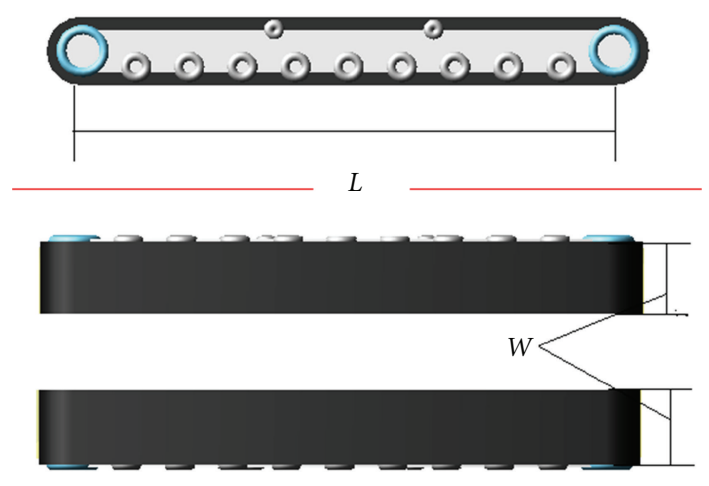

(a)

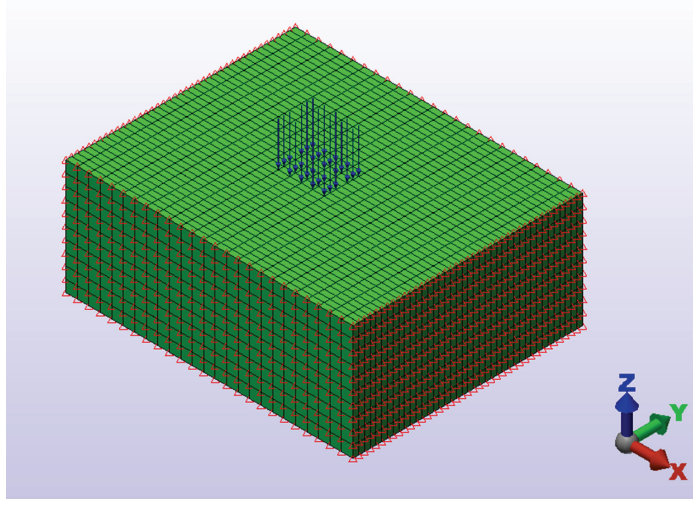

(b)

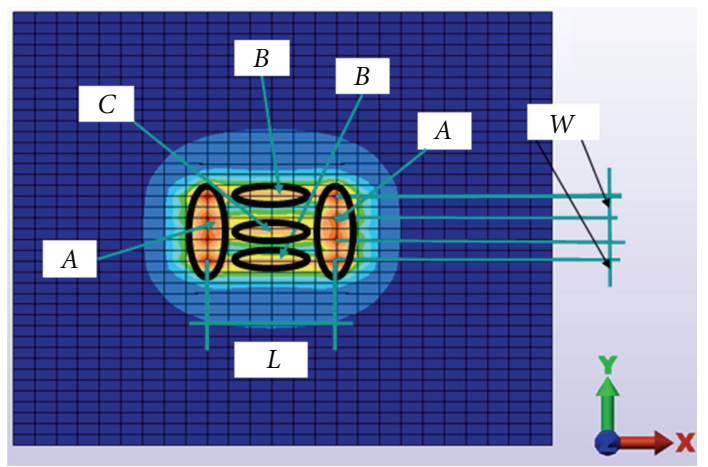

(c)

FIGURE 5: 3D finite-element model of track-oil sand terrain interaction. (a) Track structure (b) isometric view oil sand bin and (c) top view oil sand bin.

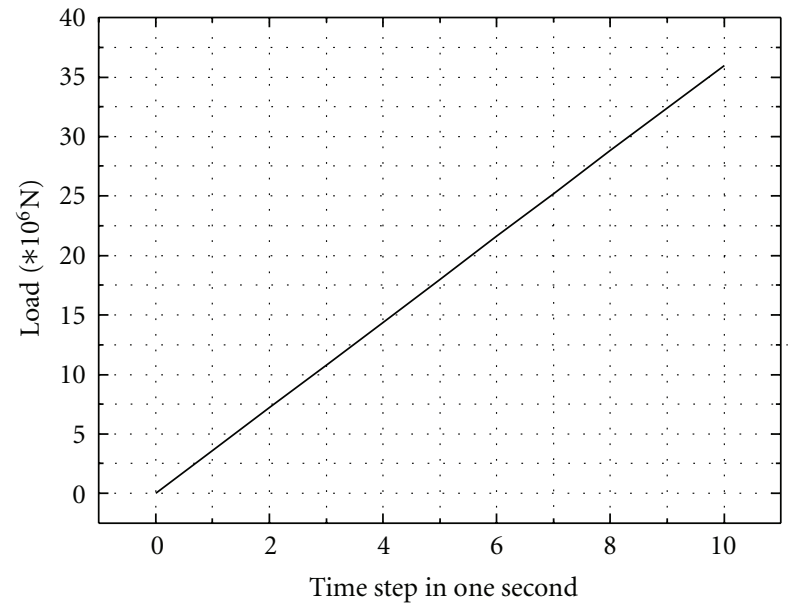

FIgURE 6: Load-time step relationship in one second.

models. The results enable ease identification of the oil sand bearing capacity and failure.

Figure 8 gives the relationships of the max stress-load and max nodal displacement load. It can be seen that the max stress increases nonlinearly with the increase of the loads from 0 to $3.6 E+7 \mathrm{~N}$, and then increases linearly with the loads from 0.1 to $0.1002 \mathrm{MPa}$ in Figure 8(a). The max stress
TABLE 1: Track pad dimensions and oil sand properties.

\begin{tabular}{lc}
\hline Each track belt length $L(\mathrm{~m})$ & $4-8$ \\
Each track belt width $W(\mathrm{~m})$ & $0.5-2$ \\
Each track contact area $A_{t}$ & $L \times W$ \\
Mass density of oil sands $\rho\left(\mathrm{kg} / \mathrm{m}^{3}\right)$ & 1600 \\
Yield stress $\sigma_{y}(\mathrm{MPa})$ & $\sim 0.1$ \\
Modulus of elasticity $E(\mathrm{MPa})$ & 10 \\
Poisson's ratio $\nu$ & 0.3 \\
Strain hardening modulus $E_{T}(\mathrm{MPa})$ & $\sim 0.1$ \\
Damping $c(\mathrm{kPa})$ & 10 \\
Environmental temperature $\left({ }^{\circ} \mathrm{C}\right)$ & 25 \\
\hline
\end{tabular}

reaches yield stress of $0.1 \mathrm{MPa}$ at the load of $3.2 E+7 \mathrm{~N}$. It is also noted that the max displacement magnitudes increase nonlinearly with loads from 0 to $3.6 E+7 \mathrm{~N}$ in Figure 8(b). The maximum max nodal displacement locals at load of $3.6 \mathrm{E}+7 \mathrm{~N}$ and minimum one does at load of $0 \mathrm{~N}$. From this model, it is easy to find that oil sands yield when the stress reaches the yield stress of $0.1 \mathrm{MPa}$. It is also noted that the nodal displacement is larger in higher load than in lower load. This result agrees with the result reported in literature [15]. 


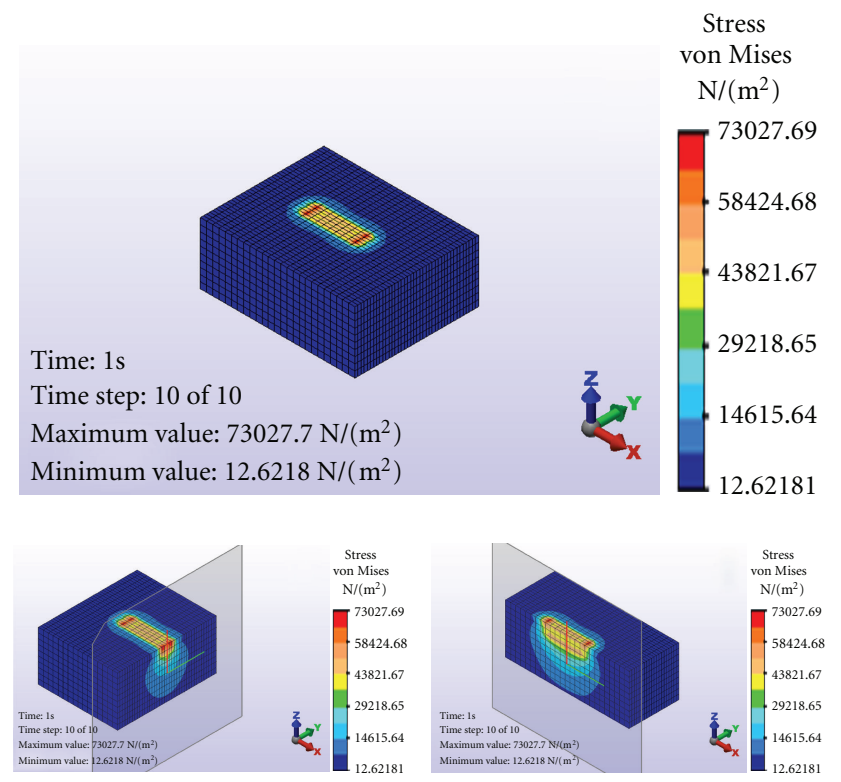

(a)
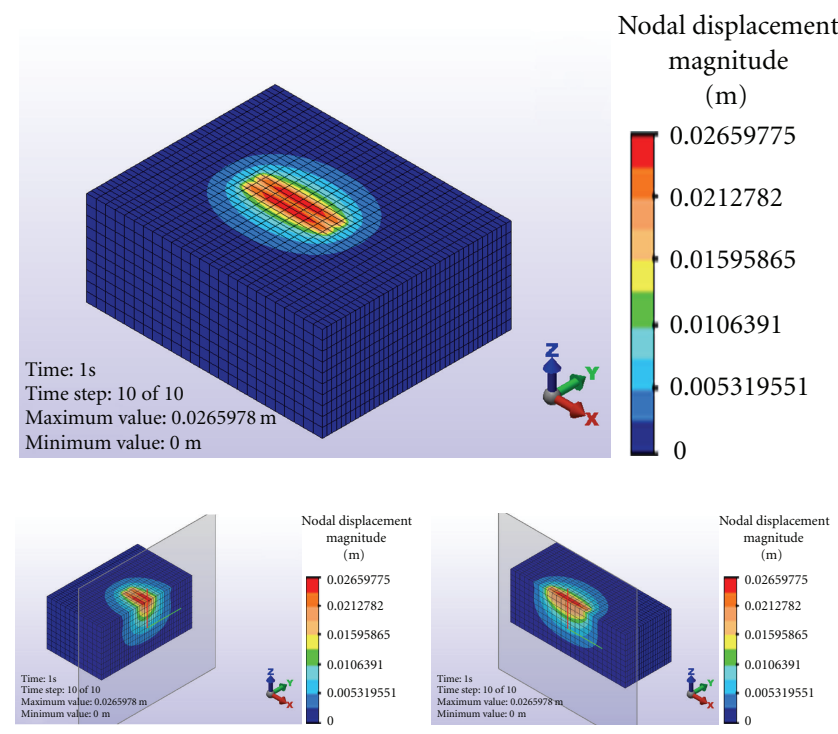

(c)

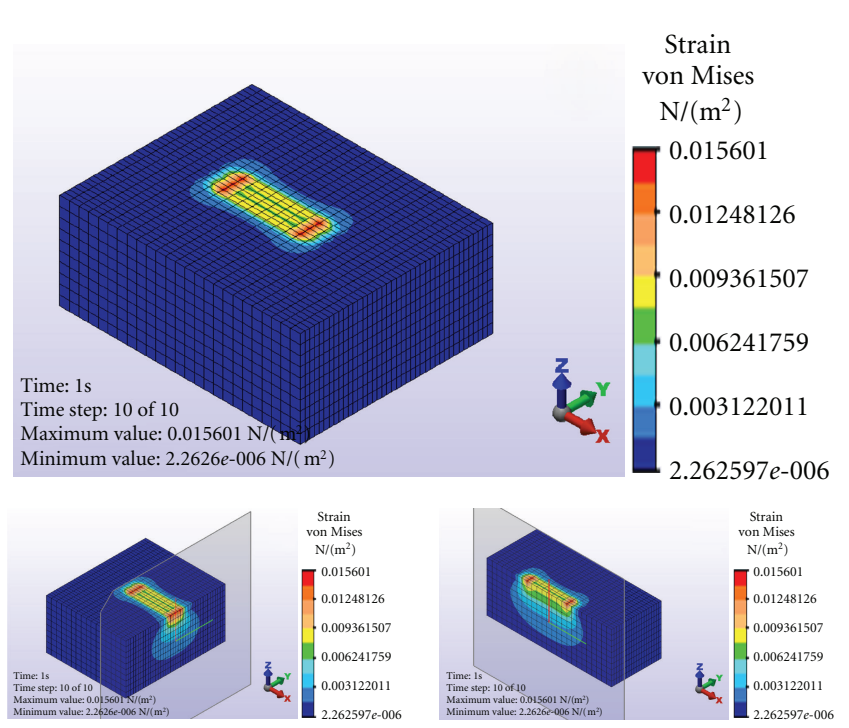

(b)
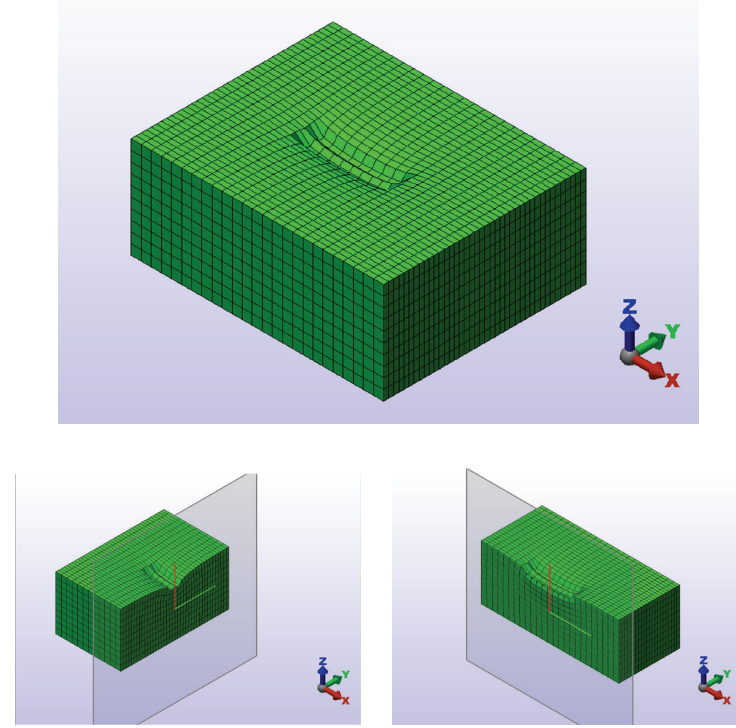

(d)

Figure 7: Oil sand contours in isometric, YZ slide, and XZ slide views. (a) Von Mises stress, (b) Von Mises strain, (c) nodal displacement, and (d) deformed shape (scale factor 5).

5.2. Effect of Load and Contact Area on Max Stress. To investigate the effect of the load and contact area between track and oil sand terrain on the max stress, the FE models are simulated with the different contact areas. The oil sand properties are given as $\rho=1600 \mathrm{~kg} / \mathrm{m}^{3}, \sigma_{y}=0.1 \mathrm{MPa}$, $E=10 \mathrm{MPa}, v=0.3, E_{T}=0.1 \mathrm{MPa}$, and $c=10 \mathrm{KPas}$. The track contact areas are set as five cases. They are case 1: $A=2 \mathrm{~m}^{2}, L=4 \mathrm{~m}$, and $W=0.5 \mathrm{~m}$; case $2: A=4 \mathrm{~m}^{2}$, $L=4 \mathrm{~m}$, and $W=1 \mathrm{~m}$; case $3: A=6 \mathrm{~m}^{2}, L=6 \mathrm{~m}$ and $W=1 \mathrm{~m}$; case $4: A=8 \mathrm{~m}^{2}, L=8 \mathrm{~m}$, and $W=1 \mathrm{~m}$; case 5: $A=10 \mathrm{~m}^{2}, L=5 \mathrm{~m}$, and $W=2 \mathrm{~m}$. The load applied to the oil sand terrain through time steps of 10 is described in Figure 6. Figure 9 represents the results of the max stress load with the load from 0 to $3.6 E+7 \mathrm{~N}$ for five cases, respectively. In general, the max stress decreases from case 1 to case 5 in Figure 9(a). From Figure 9(b), it can be seen that the max stress for case 1 increases nonlinearly with the load from 0 to $2.5 E+7 \mathrm{~N}$ and then increases linearly with a further increase load from $2.5 E+7$ to $3.6 E+7 \mathrm{~N}$. The max stress reaches yield stress of $0.1 \mathrm{MPa}$ at the load of $2.5 E+7 \mathrm{~N}$. The variations of the max stress with load for cases 1 and 2 are similar. In case 2, the max stress reaches the yield stress of 


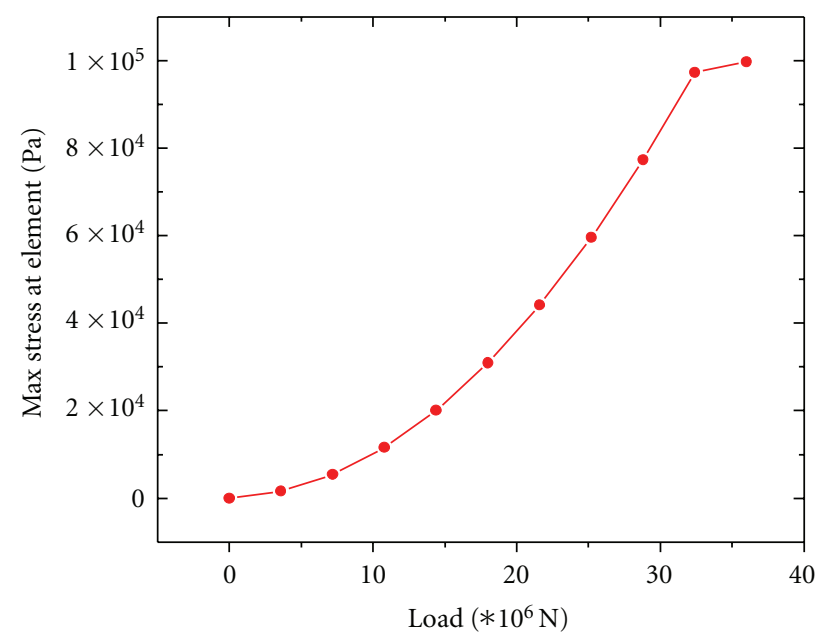

(a)

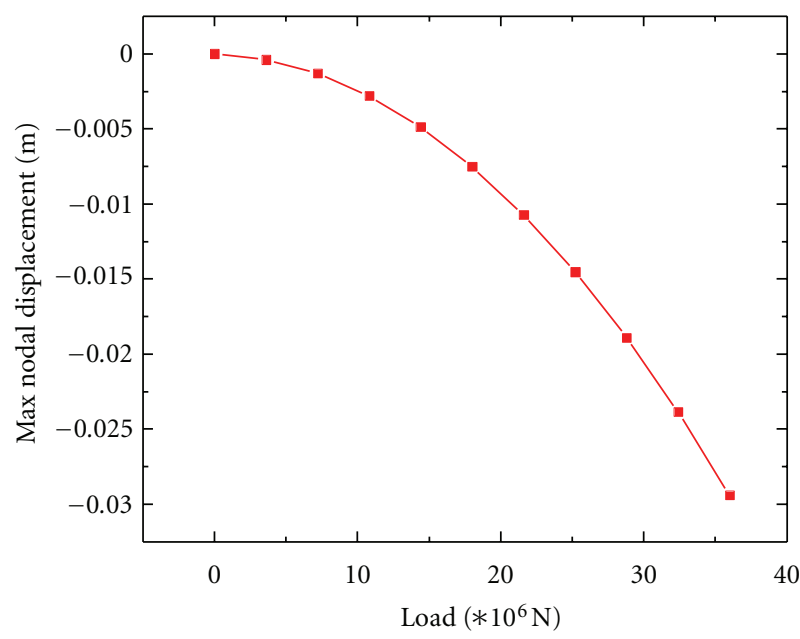

(b)

FIgure 8: Result curves. (a) Max stress load on different elements and (b) max displacement load at nodal.

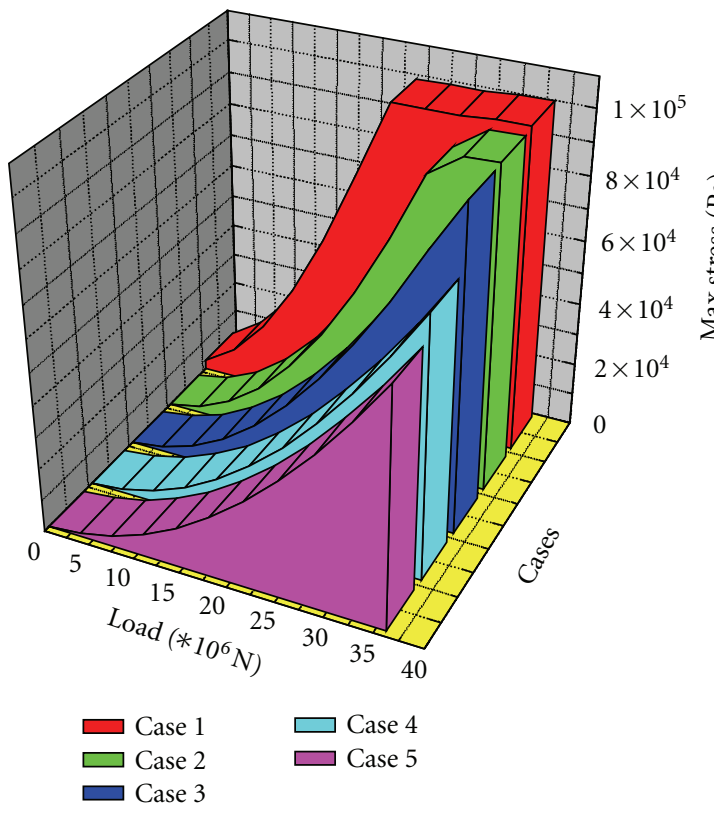

(a)

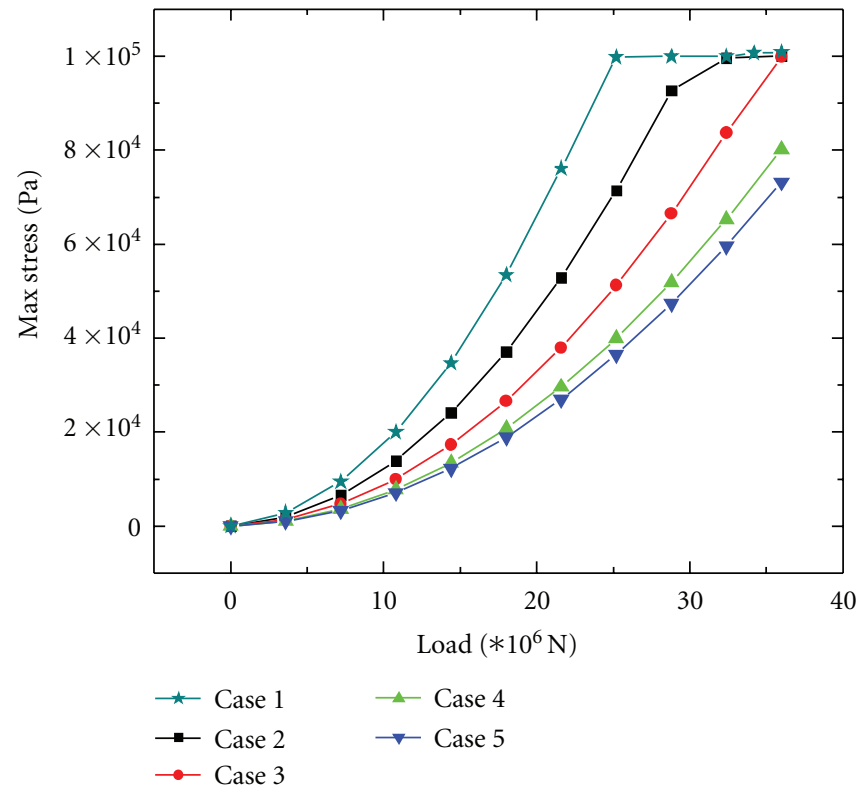

(b)

FIGURE 9: Max stress-load curves with five track contact areas against weight applied to oil sands from 0 to $3.6 E+7 N$. (a) $3 \mathrm{D}$ result and (b) $2 \mathrm{D}$ result.

$0.1 \mathrm{MPa}$ at the load of $3.2 E+7 \mathrm{~N}$. For cases 3,4 , and 5 , the max stresses increase nonlinearly with the load increase from 0 to $3.6 E+7 \mathrm{~N}$. The max stress in case 3 reaches yield stress at the load of $3.6 E+7 \mathrm{~N}$. However, the max stresses in cases 4 and 5 never reach yield stress during the load variation from 0 to $3.6 E+7 N$. For a given load, the max stress decreases from case 1 to 5 .

Figure 10 illustrates the curves of max stress-contact area with ten different loads, respectively. The loads applied to the oil sands are assumed to be $3.6 E+6,7.2 E+6,1.08 E+7$, $1.44 E+7,1.80 E+7,2.16 E+7,2.52 E+7,2.88 E+7$,
$3.24 E+7$, and $3.6 E+7 \mathrm{~N}$, respectively. In general, the max stress increases with the load from $3.6 \mathrm{E}+6$ to $3.6 \mathrm{E}+7 \mathrm{~N}$ in Figure 10(a). From Figure 10(b), it is clear that the max stresses decrease with the increase of the contact area from 2 to $10 \mathrm{~m}^{2}$. The maximum max stress locals at the contact area of $2 \mathrm{~m}^{2}$, and minimum one does at the contact area of $10 \mathrm{~m}^{2}$. It is also noted that the max stresses for the loads of $2.16 E+7,2.52 E+7,2.88 E+7,3.24 E+7$ and $3.6 E+7 \mathrm{~N}$ reaches yield stress at the contact area of $2 \mathrm{~m}^{2}$. For a given contact area, the max stress increases with load. Hence, the load and contact area shows a very significant effect on the 

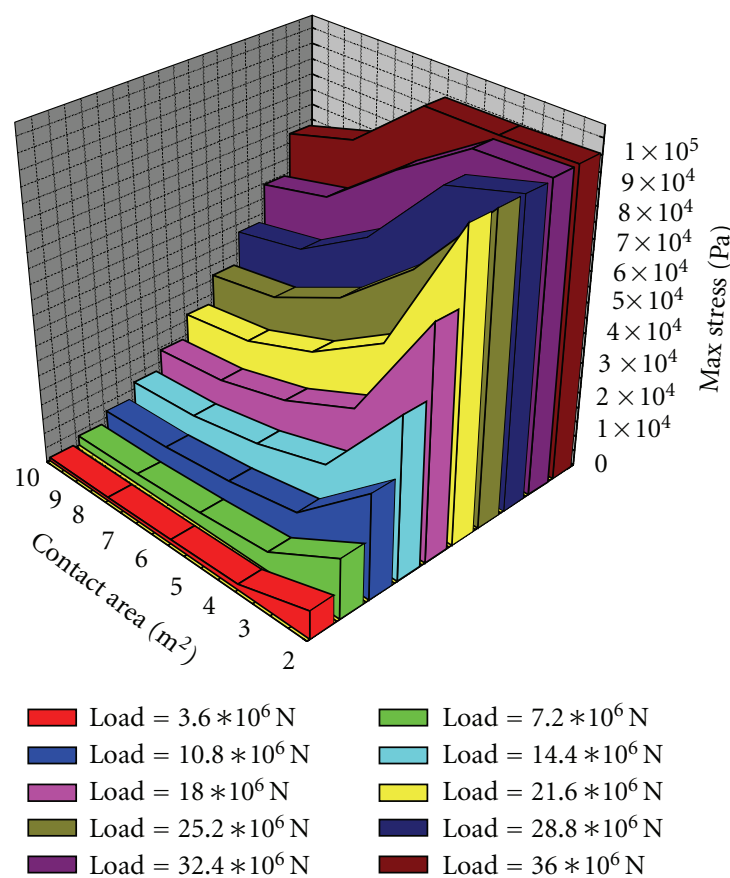

(a)

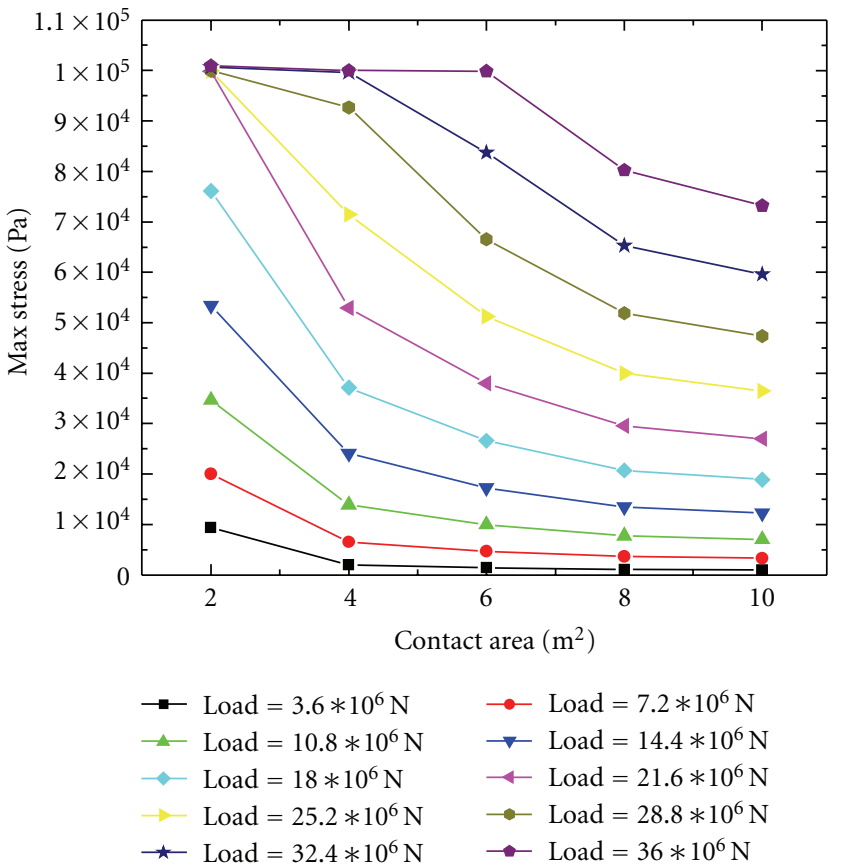

(b)

Figure 10: Max stress-contact area curves with ten loads against track-oil sand contact area from 2 to $10 \mathrm{~m}^{2}$. (a) 3D result and (b) $2 \mathrm{D}$ result.

max stress when max stress is beyond yield stress, and then this effect vanishes as the max stress is over the yield stress.

\subsection{Effect of Load and Contact Area on Max Nodal Dis-} placement. To investigate the effect of the load and contact area between track and oil sand terrain on the max nodal displacement, the FE models are simulated with the different contact areas. The oil sand properties are kept identical, and the track contact areas are still set as five cases. The load applied to the oil sand terrain through time steps of 10 is described in Figure 6. Figure 11 represents the results of max nodal displacement load with the load from 0 to $3.6 E+7 \mathrm{~N}$ for five cases, respectively. In general, the max nodal displacement decreases with case from 1 to 5 in Figure 11(a). From Figure 11(b), it is noted that the max nodal displacement magnitudes for five cases increase with the loads from 0 to $3.6 E+7 \mathrm{~N}$ nonlinearly. For a given load, the max nodal displacement decreases from case 1 to 5 this is because the contact area is increased from cases 1 to 5 .

Figure 12 illustrates the curves of the max nodal displacement-contact area with ten loads, respectively. The ten loads applied to oil sand are assumed to be identical. In general, the max nodal displacement increases with the load from $3.6 E+6$ to $3.6 E+7 \mathrm{~N}$ in Figure 12(a). From Figure 12(b) it is seen that the max nodal displacement decreases with the increase of contact area from 2 to $10 \mathrm{~m}^{2}$. The maximum max nodal displacement locals at the contact area of $2 \mathrm{~m}^{2}$, and minimum one does at the contact area of $10 \mathrm{~m}^{2}$. It is also noted that the max nodal displacements for the loads of $3.6 E+6,7.2 E+6$, and $1.08 E+7 \mathrm{~N}$ are very close at the contact area of $10 \mathrm{~m}^{2}$.
For a given contact area the max nodal displacement increases with the load from $3.6 E+6$ to $3.6 E+7 \mathrm{~N}$. Therefore, the load and contact area shows a very significant effect on the max nodal displacement.

\section{Conclusions}

A FE model for calculating the interaction of the PWA-oil sand terrain system has been developed based on the theory of soil mechanics, FEM and the Algor MES software by assuming that (i) the oil sand terrain is subjected to static load, (ii) the oil sand terrain is homogeneous, isotropic, elastic-plastic, and semi-infinite body, (iii) the track is rigid body without lug, and (iv) the load is evenly distributed over the entire contact area.

The oil sand formation was created as an elastic-plastic FE model. The von Mises yield criterion was applied to the oil sand material that has the soft skeleton and elastic-plastic behavior. An example was given for capturing the 3D behavior of the oil sand terrain in terms of stress, strain, nodal displacement, and deformation with the different loads and contact area between the track and oil sand terrain. The model validation result shows that there are the maximum stress and strain fields at the area A (see Figure 5(c)) and large displacement and deformed shade in the central loaded zone (zone B of Figure 5(c)). The simulation of the effect of the load and contact area on the max stress indicates that the load and contact area has a significant effect on the max stress when it is beyond the yield stress. For a given contact area, the max stress value increases nonlinearly with the load from 0 to $3.6 E+7 \mathrm{~N}$. For a given load, the max stress decreases with 


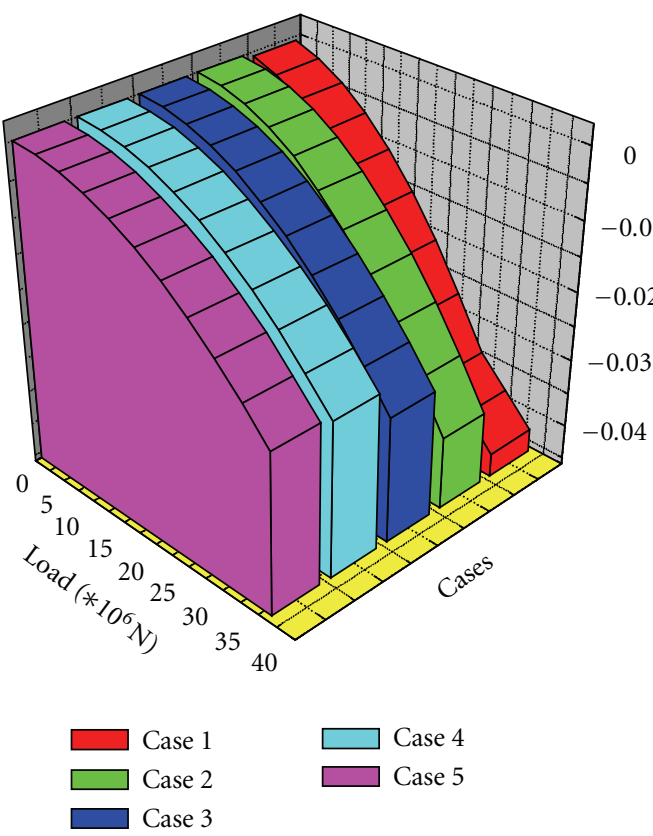

(a)

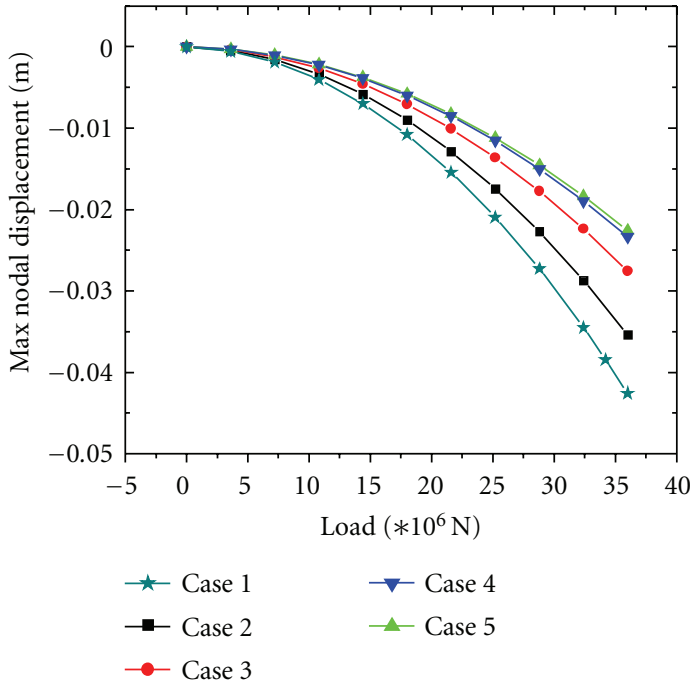

(b)

FIGURE 11: Max nodal displacement-load curves with different track contact areas against weight applied to oil sands from 0 to $3.6 E+7 \mathrm{~N}$. (a) $3 \mathrm{D}$ result and (b) $2 \mathrm{D}$ result.
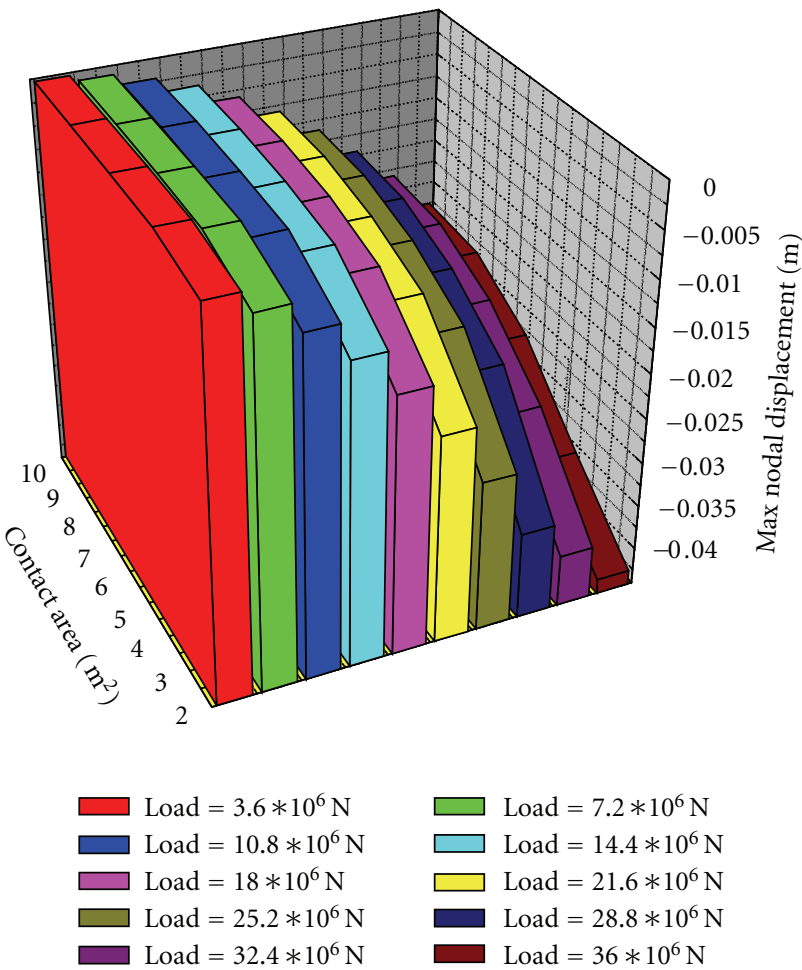

(a)

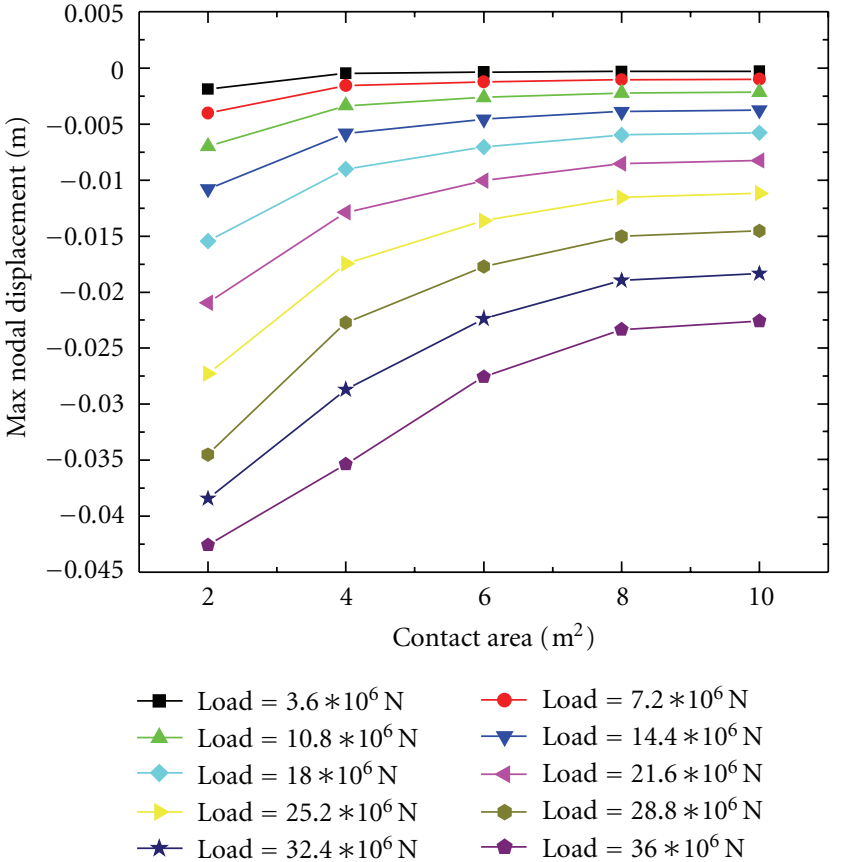

(b)

Figure 12: Max nodal displacement-contact area curves with different loads against track-oil sand contact area from 2 to $10 \mathrm{~m}^{2}$. (a) $3 \mathrm{D}$ result and (b) 2D result. 
the increase of the contact area from 2 to $10 \mathrm{~m}^{2}$. However, this effect vanishes as the max stress reaches yield stress. The simulation of the effect of the load and contact area on the max nodal displacement shows that the load and contact area have a significant effect on the max nodal displacement. For a given contact area, the max nodal displacement increases with the load from 0 to $3.6 E+7 \mathrm{~N}$. For a given load, the max nodal displacement decreases with the contact area from 2 to $10 \mathrm{~m}^{2}$.

\section{References}

[1] Y. Li, S. Frimpong, and W. Y. Liu, "Virtual prototype modeling and simulation of pipe wagon articulating system," International Journal of Modern Mechanical Engineering, vol. 1, no. 2, pp. 38-46, 2011.

[2] S. Frimpong, R. A. Oluropo, and J. Szymanski, "NUMSOSS: numerical simulation software for oil sand slurry flow in flexible pipelines," in Proceedings of the Summer Computer Simulation Conference (SCSC '03), pp. 145-154, Society for Modeling and Simulation International, Montreal, Canada, 2003.

[3] Y. Li, J. Szymanski, and S. Frimpong, "Preliminary simulation of the GAP mechanical system for oil sands haulage," International Journal of Mining, Reclamation and Environment, vol. 21, no. 4, pp. 295-305, 2007.

[4] Department of the Navy, "Naval facilities engineering command: foundations and earth structures," U.S. G.P.O., Washington, DC, USA, 1982.

[5] J. Y. Wong, Theory of Ground Vehicles, John Wiley \& Sons, New York, NY, USA, 1991.

[6] J. Y. Wong and J. Preston-Thomas, "On the characterization of the shear stress-displacement relationship of terrain," Journal of Terramechanics, vol. 19, no. 4, pp. 225-234, 1983.

[7] J. Y. Wong and Y. Gao, "Applications of a computer aided method to parametric study of tracked vehicles with rigid links," Proceedings of the Institution of Mechanical Engineers, Part D, vol. 208, no. 4, pp. 251-257, 1994.

[8] P. Lubking and M. A. Van, Building on Soft Soils, A. A. Balkema, USA, 1996.

[9] A. M. Girijavallabhan and L. C. Reese, "Finite element method for problems in soil mechanics," Journal of the Soil Mechanics and Foundations Division, vol. 94, no. 2, pp. 473-479, 1968.

[10] D. Pollock, J. V. Perumpral, and T. Kuppusamy, "Finite element analysis of multipass effects of vehicles on soil compaction," Transactions of the American Society of Agricultural Engineers, vol. 29, no. 1, pp. 45-50, 1986.

[11] I. M. Smith and D. V. Griffiths, Programming the Finite Element method, John Wiley \& Sons, New York, NY, USA, 2nd edition, 1988.

[12] Algor, "User's manual. Mechanical event simulation," 2007, http://www.Algor.com.

[13] K. J. Bathe, Finite Element Procedures in Engineering Analysis, Prentice-Hall, NJ, USA, 1982.

[14] NPL Manual, Manual for the Calculation of Elastic-Plastic Materials Models Parameters, Queen's Printer, Scotland, UK, 2007.

[15] P. K. Nainan, K. S. Beena, and R. Krishna Kumar, "Settlement of reinforced sand in foundations," Journal of Geotechnical and Geoenvironmental Engineering, vol. 123, no. 9, pp. 818-827, 1997. 

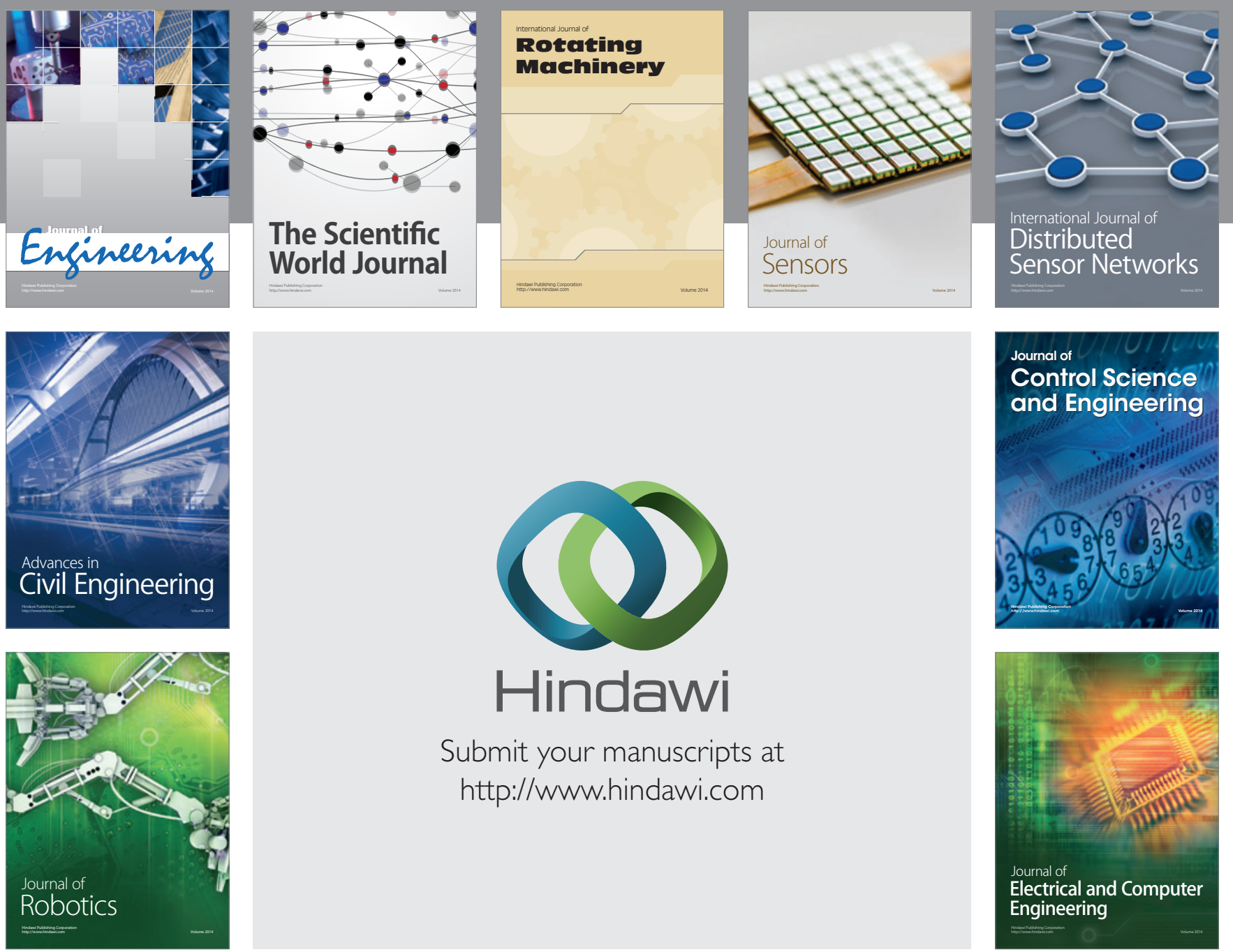

Submit your manuscripts at

http://www.hindawi.com
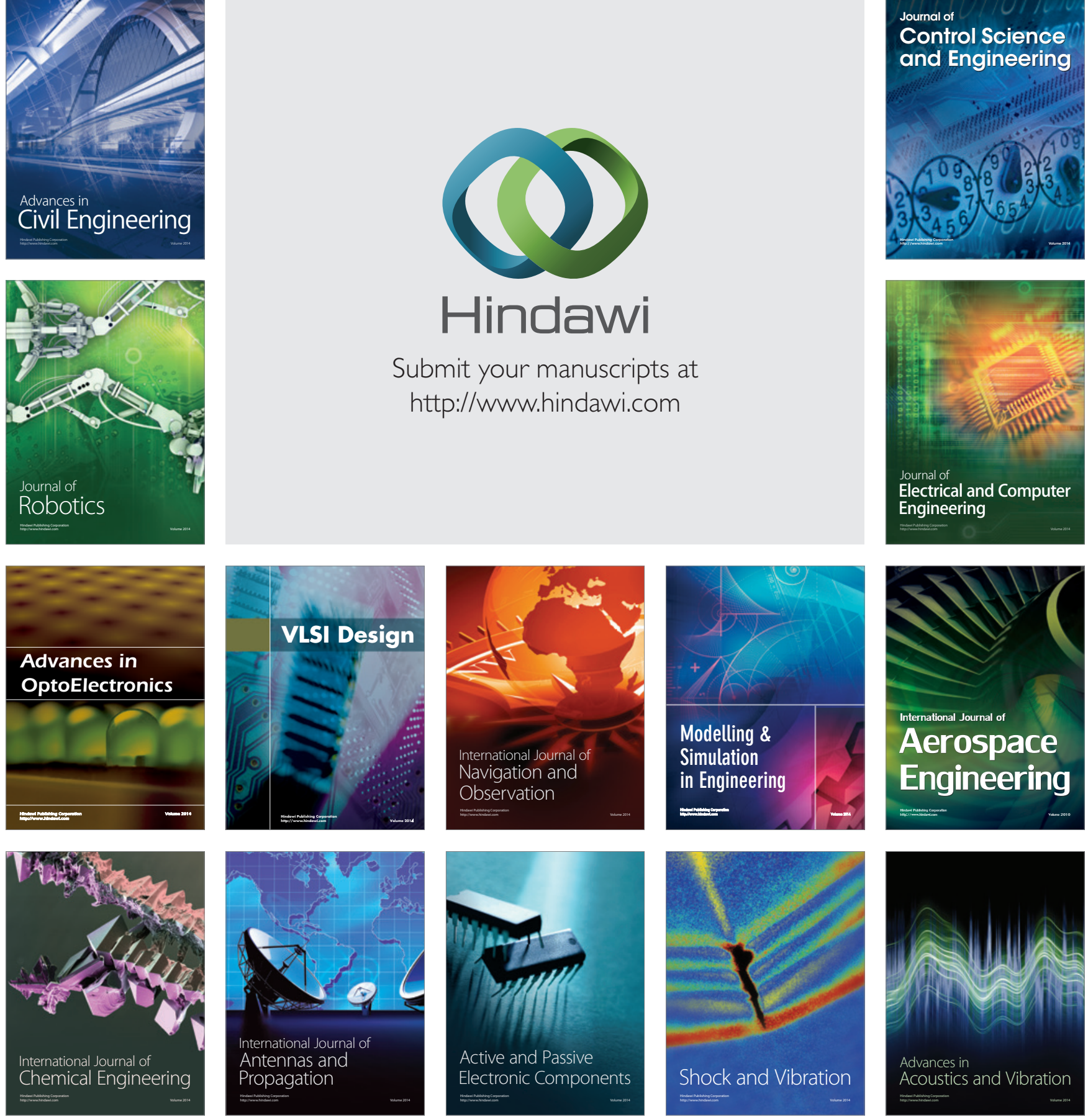